\title{
MUSCLE SPASM AS A CAUSE OF SOMATIC PAIN*
}

\author{
BY \\ DERYCK TAVERNER \\ Department of Medicine, University of Leeds
}

(RECEIVED FOR PUBLICATION JULY 19, 1954)

Pains which seem predominantly to affect the muscles are extremely common and many hypotheses regarding their genesis have been developed, but most of them have lost support in time. The concept of "fibrositis", so popular 20 years ago, is now almost universally suspect, and few would claim that any sound basis for it has been discovered.

But the destruction of a hypothesis, such as "fibrositis", does not eradicate the condition it was designed to explain. As has often been pointed out in discussion: "the pain is very real". Other theories are still current and should undergo the same critical treatment as did "fibrositis". For example, it is frequently suggested that muscle spasm is the cause of pain in a variety of disorders ranging from prolapsed intervertebral disk (Rose, 1954) to psychoneurosis (Holmes and Wolff, 1952).

It is such common knowledge that a sustained muscular contraction can be painful that it is not surprising that an involuntary muscular contraction - a muscle spasm-should be invoked as a cause of pain in disease. Indeed, this idea has led to the therapeutic use of muscle relaxants, such as $d$-tubocurarine (Schlesinger, 1946) and myanesin (Schlesinger, Drew, and Wood, 1948), but the results have not been very impressive.

It is important to examine the evidence on which the concept of muscular spasm as a common cause of pain is based. There is, of course, the clinical observation that some painful muscles are both tender and firm to the touch. Such observations may well be misleading and there have been many attempts to prove the existence of the postulated muscular spasm by instrumental methods.

Of these, electrical devices, as in electromyography, have been chiefly used, and one of the most frequently quoted contributions is that of Elliott (1944a). Elliott examined the electrical activity in muscles of fourteen patients who were later proved surgically to be suffering from prolapsed intervertebral disks. He inserted needle electrodes and

\footnotetext{
* Paper read at a meeting of the Heberden Society, May, 1954.
}

in eight patients with muscular tenderness he found increased irritability of the tender muscles, i.e. needle movement produced more spontaneous electrical activity than in controls. In some of these tender muscles he also found a continuous discharge of one or more action potentials in "otherwise relaxed muscles". His records show, and he describes, single motor unit action potentials firing at rates of $8-12 / \mathrm{sec}$. Spontaneous fluctuation of this activity was noted, i.e. a motor unit close to the electrode would disappear while more distant ones would continue. This spontaneous activity was shown to be localized to the tender areas by means of double channel recording, and it was found to disappear after infiltration with procaine. In discussing his findings, Elliott (1944b) refers to these electrical changes as muscular spasm, and suggests that this may cause pain in one of two ways: either because unphysiological muscular contraction, as in cramp, is painful, or because muscles contracting under ischaemic conditions become painful.

Other workers have investigated this problem in similar ways, but have usually obtained inconclusive results. For example, Holmes and Wolff (1952) found that psychoneurotic patients with backache showed generalized muscular hyperactivity during simple movements of one limb or during interviews provocative of conflict and hostility. This muscular activity did not invariably cause pain and the authors noted that similar amounts of vigorous muscular activity in exercise were normally well tolerated and painfree.

Before considering this evidence it is necessary to describe briefly the principles upon which electromyography is based (Weddell, Feinstein, and Pattle, 1944; Bauwens, 1948). The simplest muscle twitch is due to the contraction of a single motor unit. Increasing work results from firstly a faster rate of firing of the individual motor units, and secondly the recruitment of more motor units. A motor unit consists of one anterior horn cell, its motor nerve fibre and the hundred or more muscle fibres which it 
supplies. The fibres of the individual motor unit are dispersed to some extent and do not form a compact anatomical structure. When the anterior horn cell fires, its dependent muscle fibres contract more or less simultaneously. If a needle electrode is placed close to the motor unit, the resulting electrical activity can be recorded with suitable electronic equipment. The action potential of a single motor unit has an amplitude of 1-2 millivolts and a duration of 5-10 milliseconds. All innervated contraction of skeletal muscle is accompanied by electrical activity which can be easily detected.

In a fully relaxed normal muscle there is complete electrical silence (Fig. 1). Slight voluntary contraction produces one or more motor unit action potentials firing at rates of $5-10 / \mathrm{sec}$. As the activity increases, the rate of firing goes up to $40-50 / \mathrm{sec}$. and more and more motor units are recruited until a maximal voluntary contraction results in an interference pattern of superimposed action potentials.

In practice certain difficulties may arise. The equipment used in electromyography is rather aweinspiring, and few people relish the insertion of a large needle without an anaesthetic. Apprehension leads to muscular contraction, and one of the minor problems of electromyography is to produce the $e^{\mathbb{D}}$ complete relaxation necessary to achieve the elec- 3 trical silence mentioned. Patients who have sufferedㅁ. from severe pain, as in sciatica, for some time, find? it hard to relax satisfactorily, and anyone with $a_{\vec{s}}^{\vec{*}}$ tender muscle is likely to react to the intrusion of a needle by involuntary muscular contraction. It ise clear, therefore, that the discovery of single motor units firing spontaneously does not prove that thereo has been pre-existing spontaneous muscular activity In addition, we now know that irritation of nerve roots, e.g. by prolapsed intervertebral disks, may. sometimes produce spontaneous action potentials (Richardson, 1951). Such activity often presents in the form of groups of repetitive action potentialso with a characteristic electromyographic pattern? These bursts are often, but not necessarily, found inç tender or painful muscles and they may be observed clinically as fasciculations. There can be little doubtw that both the pain and the electrical activity are secondary to the nerve root irritation.

Spontaneous electrical activity is a common $\overrightarrow{-}$ electromyographic finding and is seldom associatedo with pain. Activity very similar in appearance to that illustrated by Elliott is a characteristic feature

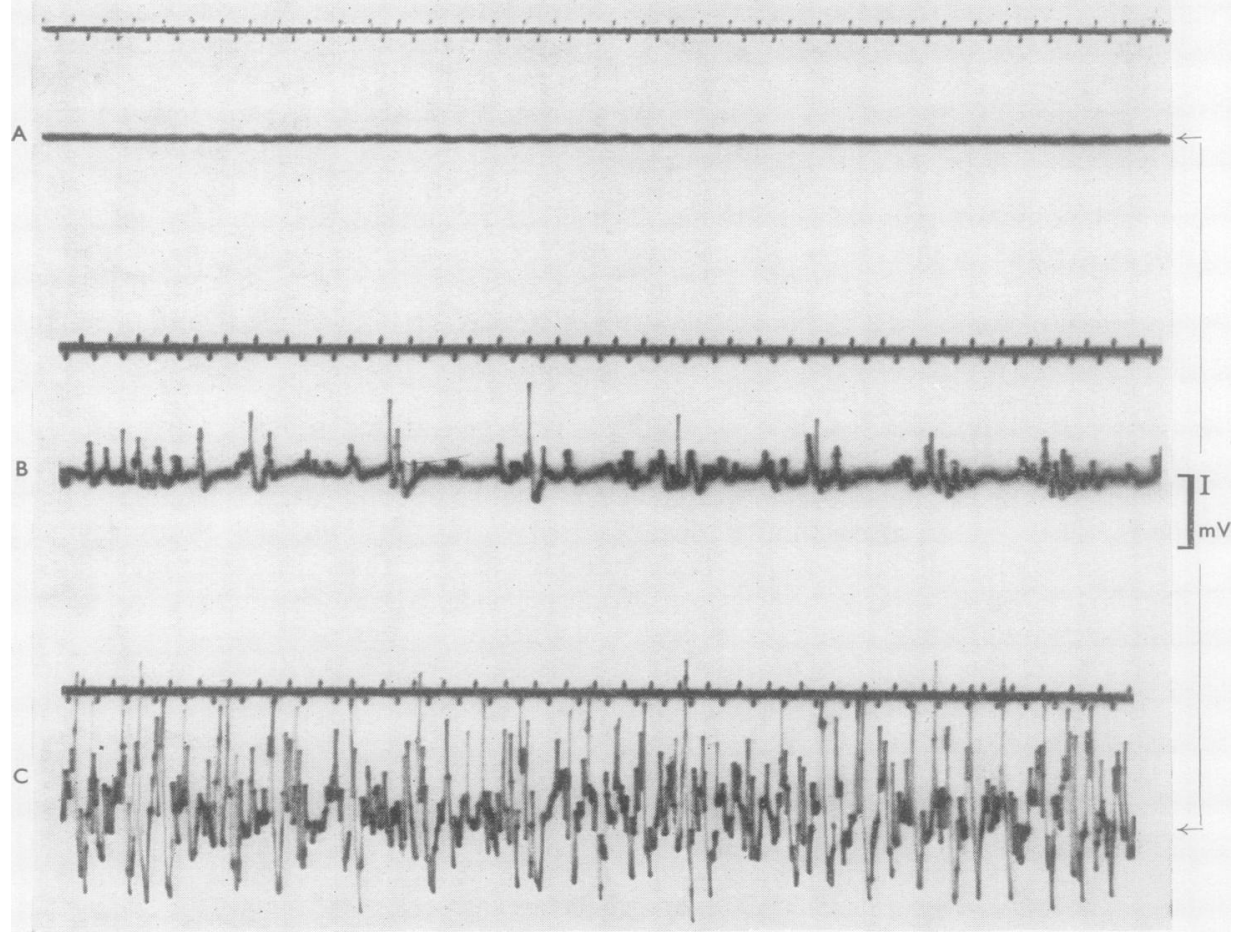

Fig. 1.-Needle electrode recordings from a normal tibialis anticus muscle. Upper beams-10 msec. time marker. Lower beams $\stackrel{\mathscr{S}}{\rightarrow}$ electrical activity of muscle. A. Resting muscle. B. Slight voluntary contraction. C. Full voluntary contraction. 


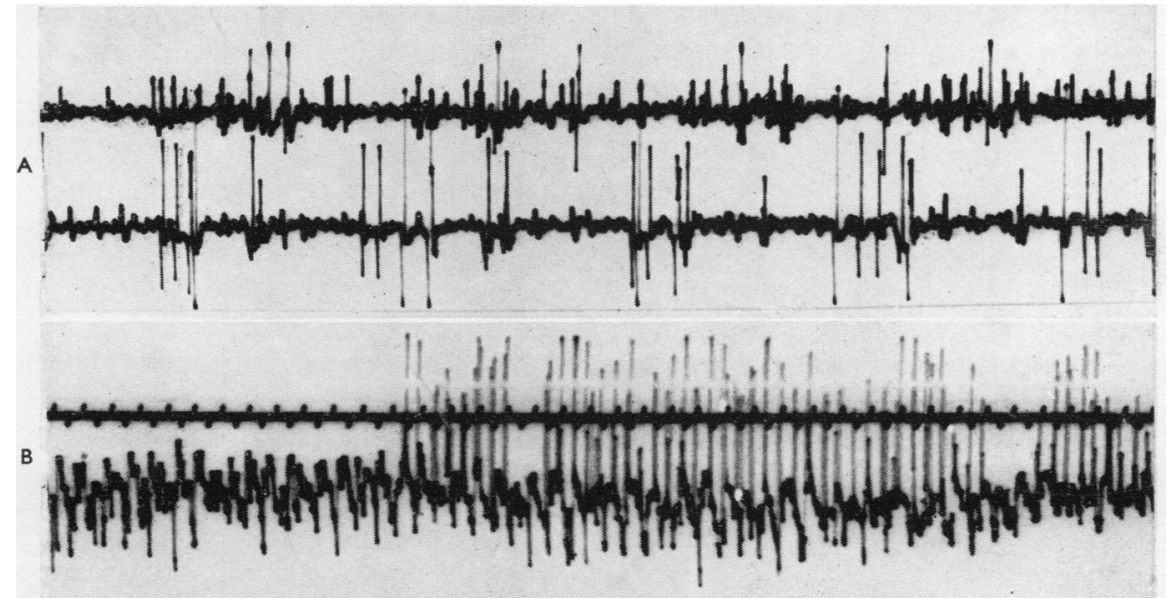

Fig. 2.-A. Simultaneous needle electrode recordings of spontaneous electrical activity from right frontalis muscle (upper beam) and right orbicularis oris muscle (lower beam) of a patient with painless facial twitching at 6 weeks' duration.

B. Needle electrode recording (lower beam) of spontaneous electrical activity in extensor communis digitorum muscle of a patient suffering from dystrophia myotonica.

of the usually painless condition, amyotrophic lateral sclerosis, and may persist for months. Fig. 2A shows a double-channel recording from the facial muscles of a patient with persistent but painless facial twitching of 6 weeks' duration. In the painless condition of dystrophia myotonica, spontaneous electrical activity of a much more striking order is constantly seen (Fig. 2B). It is true, as Elliott remarks, that muscle cramp is painful, but painful cramp is characterized by sustained electrical activity at frequencies of $300 / \mathrm{sec}$. or more (Adams, Denny-Brown, and Pearson, 1953), a frequency never achieved in the most intense voluntary contraction. Fig. 3A shows the typical appearance of high frequency activity recorded from the external oblique muscle of a patient suffering from repeated painful muscle cramps. Fig. 3в shows a recording from another patient with intense muscular spasm

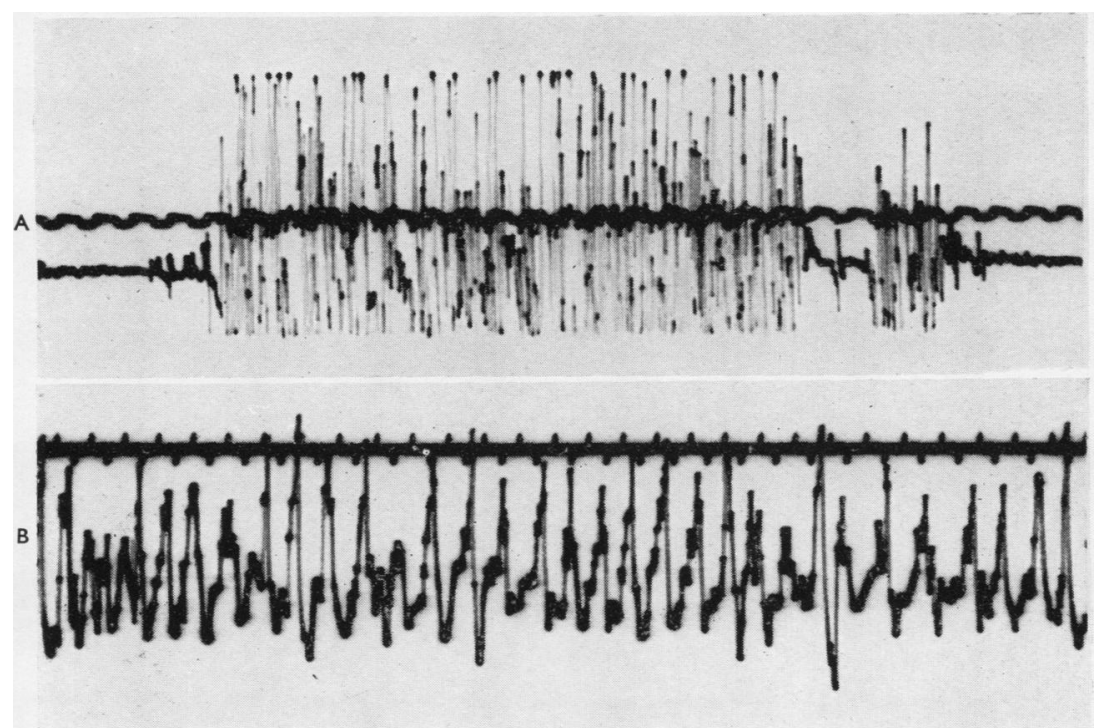

Fig. 3.-A. Needle electrode recording from external oblique muscle during a painful muscle cramp. B. Needle electrode recording from right deltoid muscle during a painless involuntary muscle contraction or spasm. 
(involuntary contraction) of his deltoid muscle. This was quite painless and it is noteworthy that the pattern is typical of a maximal voluntary contraction, but there is no sign of the high frequency activity seen in the muscle cramp.

In my own experience of electromyography in other painful conditions I have never seen spontaneous activity suggestive of cramp or, in the relaxed subject, of a degree which appeared likely to cause pain. I have, however, noted that in acute lumbago there is an abnormal degree of electrical activity in the erector spinae muscles whenever the patient makes the slightest attempt to change his position. When fully relaxed in the prone position the muscles become silent although the pain usually persists. This abnormal reactivity of the lumbar muscles is probably protective.

Yet there is no doubt that muscles do become painful after activity. The following experiment seems to exclude spasm as a cause of such muscle pain, but does raise other possibilities. The subject was a young lady who can induce typical "fibrositic" pain in the middle third of the upper border of the right trapezius muscle by knitting for about an hour. The pain leads to nausea, forces her to stop work, and is associated with marked, localized tenderness. The pain disappears in a few hours or can be immediately abolished by the injection of 1 per cent. procaine. This is a common site for such pain ang it may occur, for example, after motoring.

The subject had noticed that her pain did not develop if she knitted with her right elbow sup ported, thus slightly reducing the activity in the rigke trapezius muscle, or when knitting with the rigke arm slightly abducted, which increases the trapezius activity. Fig. 4 shows records from two needles inserted into similar areas of the two trapezii while knitting normally (Fig. 4A), which caused pain, and while knitting with the arm abducted (Fig. 4B) which did not.

Fig. 5 shows the electrical silence in the twg

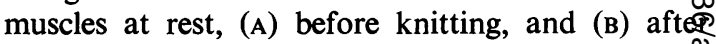
knitting when the pain was severe.

It is evident that there is no sign of musculain spasm under the conditions of this experiment. It is also of interest that increasing the activity of the righto trapezius muscle actually prevented the onset of pain. When the subject is knitting normally, the electrical activity in the two trapezii is the same, yet pain only occurs on the right side. This girl has a slightly "dropped" right shoulder, and this corrected by supporting the right elbow, which alse prevents the development of the pain. It seen possible that the initial length of the contracting muscle may be a factor, but further study is neeges

There is little reliable evidence in support of $\mathrm{hte}_{\mathrm{e}}$

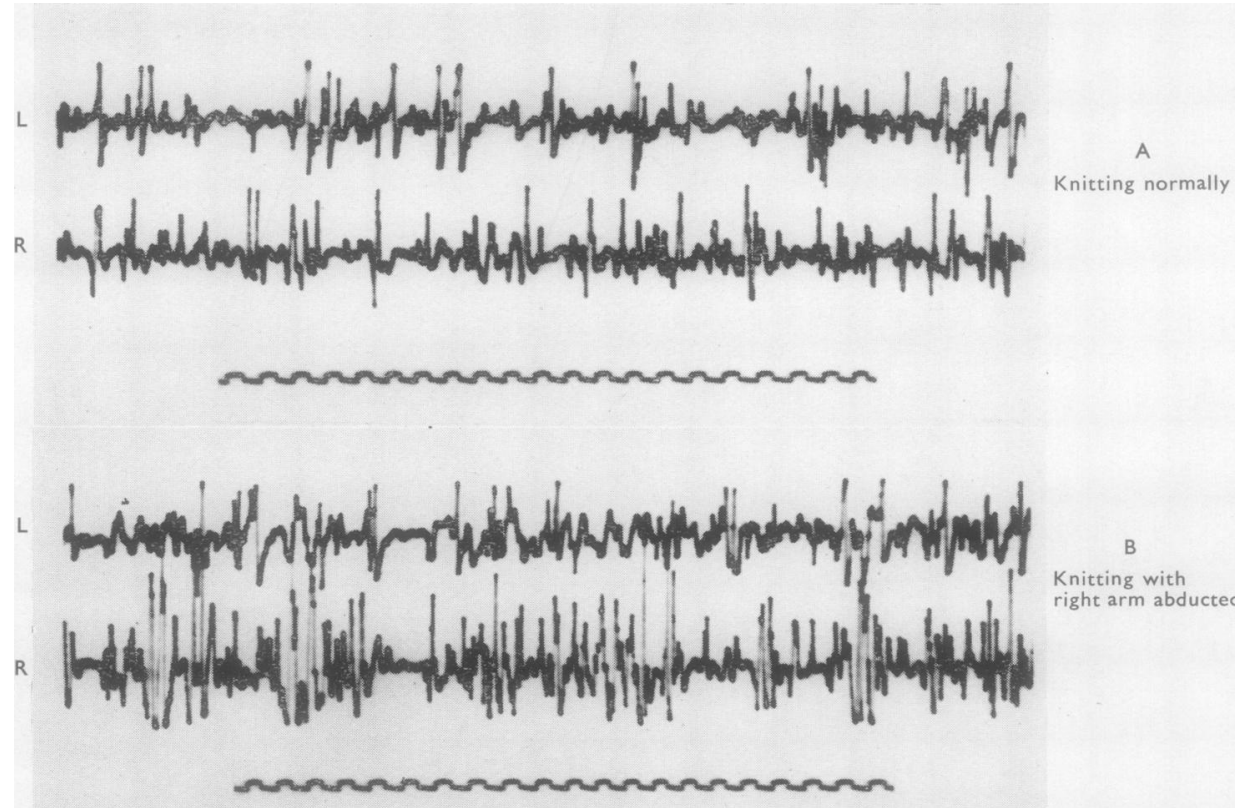

Fig. 4.-Simultaneous needle electrode recordings from symmetrical situations in the trapezii of a normal subject during knitting with right arm in normal position (A) and abducted (B). 


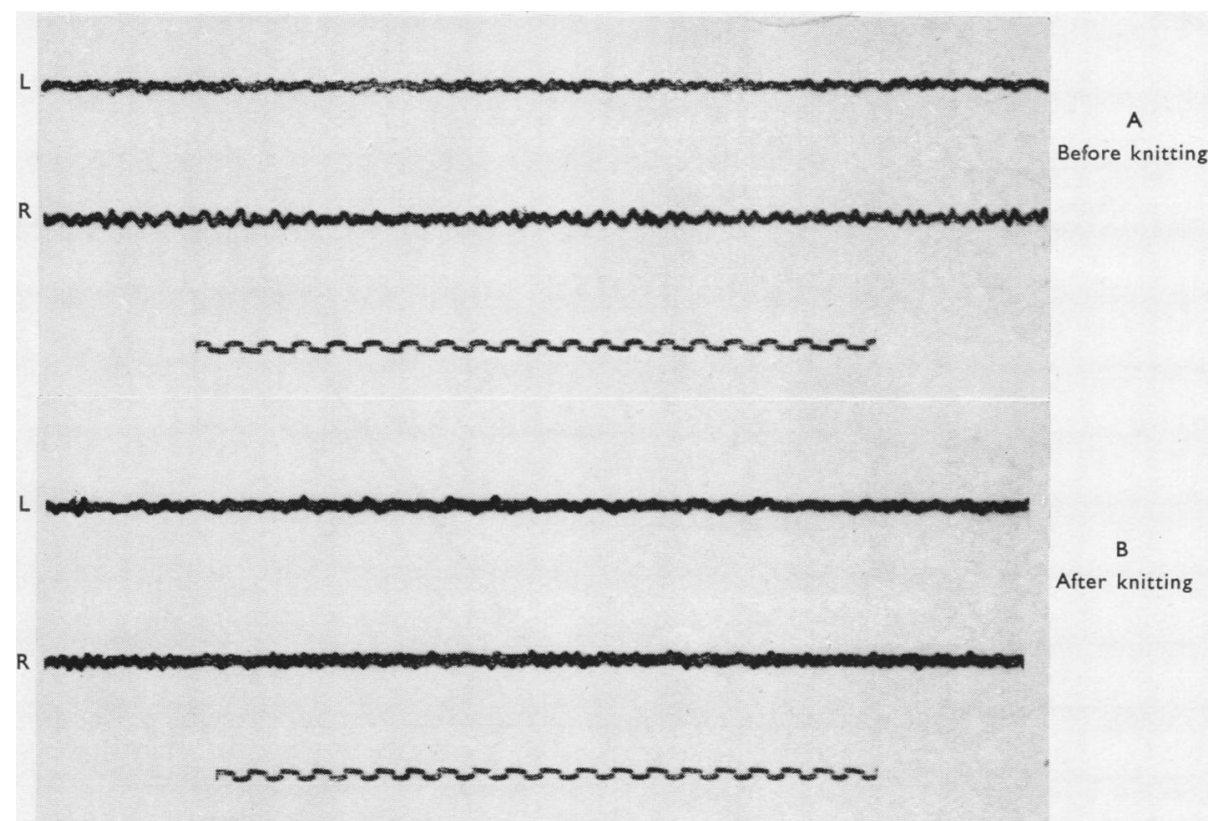

Fig. 5.-Similar needle positions to Fig. 4 to show electrical silence before knitting (A) and after knitting (B) when severe "fibrositic" pain had been induced on the right side.

theory that muscle spasm is the direct cause of somatic pain, in most cases at any rate. Tired muscles are painful, and in this sense pain in certain psychoneurotics may perhaps result from unnecessary or exaggerated muscular activity. In this connexion it may be of importance that tiredness and exhaustion are very common symptoms in these patients.

\section{Summary}

(1) The evidence supporting the concept of muscle spasm as a common cause of skeletal pain is reviewed.

(2) Similar sustained electrical activity is found in many painless conditions.

(3) The characteristic high frequency activity of painful muscular cramp is contrasted with the relative or complete electrical silence of the skeletal muscles in most somatic pains.

(4) An experiment is described in which "fibrositic" pain was induced without any electrical evidence of muscular spasm.

\section{REFERENCES}

Adams, R. D., Denny-Brown, D., and Pearson, C. M. (1953). "Diseases of Muscle". Cassell, London.

Bauwens, P. (1948). Brit. J. phys. Med., 11, 130. Elliott, F. A. (1944a). Lancet, 1, 47.

- (1944b). Annals of the Rheumatic Diseases, 4, 22.

Holmes, T. H., and Wolf, H. G. (1952). Psychosom. Med., 14, 18.

Richardson, A. T. (1951). Arch. phys. Med., 32, 199.
Rose, G. K. (1954). Lancet, 1, 1143.

Schlesinger, E. B. (1946). Bull. N.Y. Acad. Med., 22, 520.

- Drew, A. L., and Wood, B. (1948). Amer. J. Med., 4, 365.

Weddell, G., Feinstein, B., and Pattle, R. E. (1944). Brain, 67, 178

Spasme musculaire comme cause de douleur somatique

\section{RÉsUMÉ}

(1) On passe en revue la conception du spasme musculaire comme cause de la douleur organique.

(2) On trouve une activité électrique soutenue similaire dans beaucoup d'affections indolores.

(3) On oppose l'activité caractéristique de haute fréquence de la crampe musculaire douloureuse au silence électrique relatif ou complet des muscles striés dans la plupart des douleurs organiques.

(4) On décrit une expérience dans laquelle on avait provoqué une douleur de "fibrosite" sans aucune manifestation électrique de spasme musculaire.

Espasmo muscular como causa de dolor somático

\section{Sumario}

(1) Se pasa en revista el concepto del espasmo muscular como causa de dolor orgánico.

(2) Actividad eléctrica sostenida similar fué encontrada en muchas afecciones sin dolor.

(3) Se contrasta la actividad característica de alta frecuencia del calambre muscular doloroso con el silencio eléctrico relativo o completo de los músculos estriados en la mayoría de los dolores somáticos.

(4) Se describe un experimento en que un dolor "fibrosítico" fué provocado sin manifestación eléctrica alguna de espasmo muscular. 